\title{
Competencies and Work Practices for Dynamic Distributed Software Development in Global Value Networks
}

\author{
Mikko Ruohonen ${ }^{1}$, Marko Mäkipää ${ }^{1}$, and Pekka Kamaja ${ }^{2}$ \\ ${ }^{1}$ University of Tampere, Finland \\ ${ }^{2}$ Haaga-Helia University of Applied Sciences, Finland \\ \{mikko.j.ruohonen, marko.makipaa\}@uta.fi, \\ pekka.kamaja@haaga-helia.fi
}

\begin{abstract}
Offshoring of software development (SD) to cost competitive countries (CCC) has gained increased popularity in US and Western Europe since year 2000. Countries, such as India, have dominated the discussion but now it also seems that not just the labor costs matter. In the future, service levels, dynamic competencies building and community-based activities are also needed for managing dynamic distributed software development (DDSD) work. Instead of the one-way migration of RDI operations there are increasingly voices questioning the rationale of moving operations to CCCs. The key driver of this research-in-progress paper is in searching a new frameworks, tools and practices for managing DDSD work and developing SD operations evaluation solutions. The forthcoming practical outcomes described are both the improvements in SD work in the industry level and provision of enhancements for their current SD work performance assessment. Academic results will be discussed with European, US and Indian partner researchers in the context of changing dynamic sourcing i.e. onshore, nearshore, offshore activities in global value networks. The general objectives are to improve ICT-services companies' competencies and tools in i) assessing their SD work operations with more enhanced evaluation systems and ii) make visible practices in managing dynamic distributed sourcing network operations in global value networks.
\end{abstract}

Keywords: Software development, competencies, distributed work practices, global software engineering, dynamic offshoring

\section{Background and Rationale}

Offshoring of software development to cost competitive countries has gained increased publicity in US and Western Europe since year 2000. India, China and even Latin America have been mentioned as potential cost competitive countries [1] [2] [3]. Outsourcing of both information technology (ITO) and business and knowledge processes (BPO/KPO) has increased during the last two decades and now provides increasing business opportunities [4] [5] [6]. Cost competitive countries have dominated although it seems that not just the labor costs matter. In the future, service 
levels, dynamic competencies and community-based activities are also needed for managing dynamic distributed software development work. Cultural fit and suitability of administrative environment are important to notify when making outsourcing decisions [7]. Outsourcing is too often considered one-sided: handing over assets, people, activities and knowledge to third-party management, but it can also be a contract for two-way collaboration to release your own knowledge and learning potential, while also releasing the provider's potential, for mutual gain [8].

India has been a long time the giant of offshoring, but China has also grown. We must also remember that Latin America countries such as Brazil, Mexico and Chile and East European countries such as Poland, Czech Republic and Hungary are growing and competing in this arena. In addition onshoring, i.e. keeping work inside your home country, is still a potential alternative for maintaining responsiveness, quality control and agility. This makes a challenging decision making arena for many software development companies. Strategic offshoring has created different business models which are in a state of flux. Organizations are looking for new managerial practices and comparisons of near- and offshoring models are frequently done.

\section{Competencies for Distributed Dynamic Software Development}

\subsection{Strategy Demands New Competencies}

The background of this paper is that software development companies are willing to assess new knowledge for arguing the research, development and innovation (RDI) operations in their home or foreign countries to make a successful combination of onshoring, nearshoring and offshoring settings. Public discussion in many countries has been quite intensive before and after large outsourcing decisions. As it is noted, the low cost resources are not that clear when the impact of the hidden costs due to human resource management complexities or other structural and administrative issues related to business cultures in South and South-East Asian countries are considered.

Consequently the key driver of this research project is in searching new frameworks, tools and practices for managing dynamic distributed software development (DDSD) work and developing operations evaluation solutions. Therefore, the practical outcomes from this project are both the improvements in SD work management in the ICT industry level as well and provision of enhancements on their current performance management of software development. The overall goal encompasses the tools for management in adopting company management practices globally. Also, the optimization of the division of the RDI resources within the multitude of current and potential locations globally is considered.

Pure offshore outsourcing is changing to a more strategic direction which makes both onshoring, nearshoring and offshoring a number of viable ways to implement software development. The process is bi-directional. For example, Indian IT-service giants have during the last years increasingly acquired shared services companies or invested in nearshoring operations in USA, Latin America and Europe. 
India seems to be the most attractive country despite the promises of Chinese sourcing markets. Latin America and East European countries are joining the race. The fairly new EU member states are attractive for ICT services and also growing their ITO/BPO services exports. For the whole picture we should remember that the global sales of IT services is plus 1 trillion USD [9] of which US-based companies such as IBM and Accenture normally take 60\% market share. It is estimated [10] that total exports of Indian information technology enabled services (ITES) and business process outsourcing (BPO) business on financial year (FY) 2014 is on the level of 8487 BUSD and the global market share approximately 4-5\%. New EU countries are getting increasingly more visibility and growth.

Strategic offshoring has created different business models which are now in a state of flux. Network strategy requires development of value network to face growing and varying needs of customers. Indian companies attempt to move forward in the value chain in order to foster partnership and make customer innovations. Indian ICT service companies, previously known as "body shopping organizations" [11], are now moving to countries with lower salary costs such as Vietnam, investing in Tier II cities such as Pune, Chandigarh, Jaipur in India to get lower costs of operations and better supply of manpower, set up excellence centers in China for using huge potential of Chinese engineering workforce and acquire IT companies from Europe and Latin America to get closer to customers. Indian companies are really networking to be nearer the customer but in the same time making effectiveness in their engineering work development. In addition to that Indian ICT service companies are heading for building vertical-specific service expertise in many industries and upgrading their knowledge in so-called business transformation outsourcing. Traditionally customer intimacy has been the competitive weapon for US and European ICT service companies. This strategy is based on middle-man model in which companies which are culturally nearer to customer can also use the costeffective offshore sourcing. The third model is to set up your own captive development center i.e. to execute internal offshoring.

\subsection{Competencies for Advanced Performance Management}

Combining efficiency, productivity and effectiveness assessment makes an integrated framework. The studies of IBM [12] show interesting rationale for the project's performance management research. With eight selected topics researchers have found a clear link between business performance and software development work evaluation. Some challenges in measuring and managing software projects arise due to separate teams focused on development, build, testing, and deployment each having stove-piped processes. This leads to lack of timely information and in-context, objective, and honest assessment and insight into the status of software delivery projects. These challenges result even if all of the project members are co-located and working on a homogeneous environment.

The picture of software development gets more complicated when we add three additional dimensions commonly seen with many software delivery organizations: 
- geographical/regional distribution of team members which adds poor communication, language, culture, time challenges and process gaps resulting in reworking,

- crossing organizational boundaries which leads to lack of effective collaboration, weak project governance, lack of domain expertise, poor line of business oversight, security of IP when outsourcing and

- multiple team and heterogeneous infrastructure which adds more challenges to incompatible tools and repositories, unreliable access artifacts, lengthy onboarding and inflexible tooling integration.

The dynamic distributed sourcing network is also evolving continuously. Therefore, we need managerial decision-making for finding the most successful teams, effective locations to source, combination of talents, balanced levels and a follow-up of product/service life-cycles.

\subsection{Multicultural Competencies for Global Software Engineering}

In addition to pure labor costs knowledge management, customer learning, managing different modes and lifecycles affect the final outcomes of dynamic distributed sourcing of software development. Multicultural project teams have a higher potential for success than single-culture teams do, but they also have a higher potential for failure. Even highly data-driven projects need to be carefully managed across cultures. We say: "it's the people, not the technologies, that spell or dispel success". Cultural differences in project management can be difficult to navigate, but whether or not you agree with the benefits of globalization, its effects will be felt for a long time to come, especially in the engineering industry. Taking the time to understand how culture affects a project and an organization not only makes smart business sense but also makes our everyday work life smoother and easier--the improved flow is priceless [13].

It is vital to acknowledge the importance of cultural competence in order to act effectively and successfully in foreign cultures or in multicultural organizations. The concept of cultural competence is divided in knowledge, mindfulness and behavioral skills [14]. Knowledge comprises information about the concept of culture, the ways culture affects behavior and different cultures. Mindfulness means mediating between knowledge and behavior. It means, for example, paying attention to our own assumptions of different cultures, breaking free of stereotypes and readiness to adjust our opinions of others. Acquiring behavioral skills means extending the set of possible behavioral ways and knowing in which situation and in which culture to use each one. Increasing cultural competence is a continuous process that can take considerable time. A good starting point for increasing cultural competence is offered by different cultural typologies.

One of the most widely accepted cultural typologies is presented by Hofstede [15] [16] [17]. He distinguished cultures based on the differences in what they value and found five dimensions: power distance, uncertainty avoidance, individualismcollectivism, masculinity-femininity and long-term orientation. Trompenaars and 
Hampden-Turner [18] have identified seven dimensions by which cultures can be differentiated. Five of these dimensions depict relationships among people: universalism-particularism, individualism-collectivism, specific versus diffuse, neutral versus affective and achievement versus ascription. The other two dimensions are time perspective and relationship with the environment. House et al. [19] have presented nine dimensions in the GLOBE study of 62 societies, which help to understand the influence of cultural differences on leadership of organizations. These are power distance, uncertainty avoidance, human orientation, institutional collectivism, in-group collectivism, assertiveness, gender egalitarianism, future orientation and performance orientation.

The advantage of these models lies in their power to make sense of different cultures even if one does not have first-hand experience of a specific culture. However, the risk arises, that the models tend to simplify different cultures too much. For example, when we consider a country like India with many languages, castes and different living environments, it becomes evident that there is not a single homogenous Indian culture. According Jacob [20] most countries are culturally heterogeneous consisting of several sub-cultures, which diminishes the value of cultural typologies describing whole nations. Instead of force-fitting countries in different classes, Jacob suggests the concept of crossvergence, which means "fusing together management practices of two or more cultures, so that a practice relevant to a heterogeneous culture can be assembled". As Jacob (ibid) states, the success of crosscultural managers is not defined by their knowledge of different culture typologies or ability to classify cultures, but more in their ability to find out what kind of leadership behavior best fits the culture and their ability to develop their own managerial skills according to that. More generally speaking, Fontaine [21] gives two general focus areas for management in terms of cross-cultural management: understanding the past of the culture and shaping the future culture. As important as it is to understand the past of the culture, as we have seen in the number of studies concentrating on that, the more important it is to find ways to shape the future.

\section{$3 \quad$ Research Settings: Questions, Approach, Results}

The general objective of the project is to improve ICT-service (focused on software development ) companies' competencies and tools in i) assessing their software development work operations with more enhanced evaluation systems and ii) make visible work practices in managing dynamic distributed sourcing network operations in global value networks. This will improve ICT software sector to understand the changing sourcing environment of software development and service, detect their competencies in executing this work in different project and work settings and enable dynamic sourcing with multiple sites. The forthcoming results would be:

1. integrated framework for evaluation software development operations efficiency, productivity and effectiveness indicators (financial, quality and organizational measures) 
2. creation of managerial practices for dynamic distributed software development sourcing networks and

3. comparison guidelines for evaluating multiple sourcing sites and locations both in Finnish/European and international offshore settings.

The final goal is that the Finnish/European ICT and software industry can use these evaluation, work alignment and managerial practices for more agile and effective sourcing location management. This will make sourcing decisions more visible and easier to implement and provide agility for operations. Our research questions are:

1. How to find meaningful performance areas and create usable measures beyond traditional financial measures?

2. What are the topical areas for integrated evaluation framework and multisite sourcing management?

3. What are the competencies needed for creating and using implementable managerial work practices for multisite/location management?

Outsourcing research in the context of work organizational management is a research field which needs both knowledge from information systems/software development (IS/SD) research, organizational development and work process management research. Evaluation and performance management literature is also needed in this project.

Our methodological approach in this project will be design/action research with participating companies [22] [23]. In design research researchers and company representatives are both creating new artefacts and evaluating them. It involves interplay of theoretical backgrounds and empirical investigations to produce viable, practical outcomes.

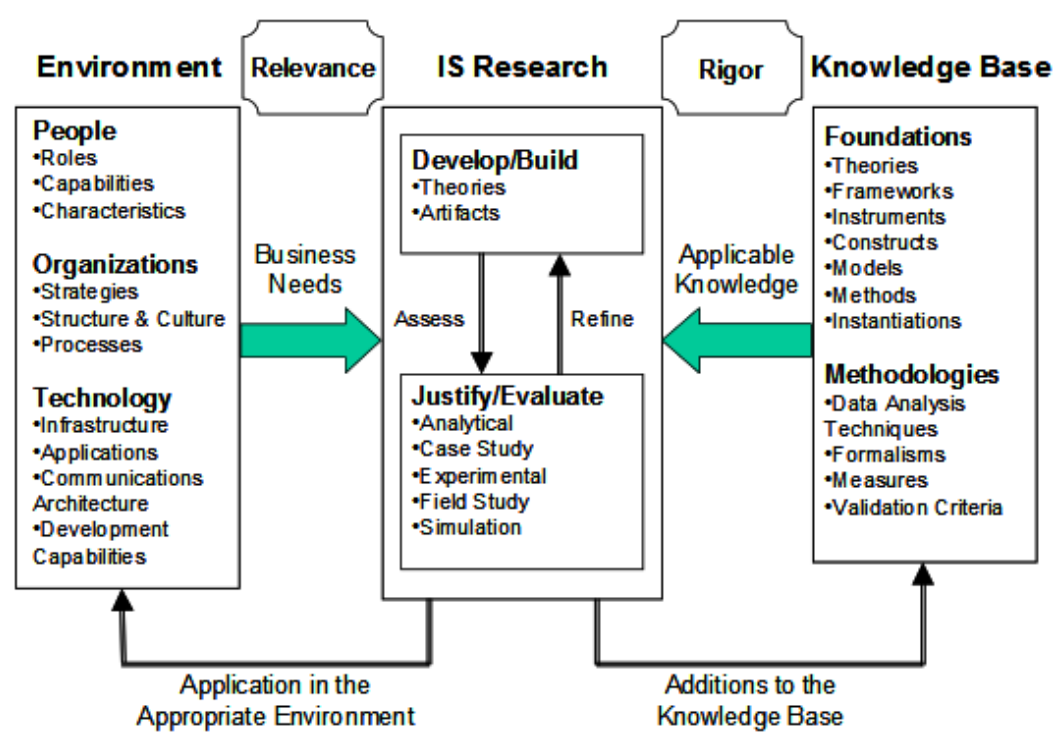

Fig. 1. Information systems research in design research [22] 


\section{$4 \quad$ Participating Companies; Minicase Descriptions}

\subsection{Minicase 1: New Ways of Managing Productivity - Case C PLC}

Our first company, Case $\mathrm{C}$, is an international software and services company specialized in telecommunications industry. The headquarters is located in Finland and in addition to that it has offices in 16 other locations in Asia, Europe, Middle-East and Australia. Net sales of the $\mathrm{C}$ group was 82.7 MEUR and the personnel approx. 700 employees on Y2013.

Since 1986 case $C$ has helped more than 290 service providers across 86 countries to meet over one billion subscribers' communications and infotainment needs. C's service fulfilment, mediation, charging and policy control, and predictive social analytics products with implementation and professional services enable service providers to automate customer interactions and other business decisions for creating revenue, reduce costs and lessen churn.

The starting point in the DD-SCALE project of $\mathrm{C}$ is the increased interest in improving the monitoring of the capabilities involved in the efficiency monitoring practices. Secondly, the company is seeking solution to monitor the site specific efficiency figures that would increase the capability of managing the distribution of $C$ 's global research, development and innovation (RDI) resources.

C's solutions are built within its global RDI network. Various metrics are collected from sites, teams and programs, which are shared in multiple dashboards. RDI productivity is an area, where only limited metrics are available. The case company aims to get more fact-based information and tools from the DD-SCALE project for monitoring and managing productivity of the teams. A key strength of this project is data normalization across multiple companies.

\subsection{Minicase 2: Advanced, Large Scale SD Work Evaluation - Case S PLC}

The second company, Case $\mathrm{S}$, is a large telecom network software and technology company with the full year sales of S 11.2 BEUR on Y2013. The number of employees is plus 20000 . Company claims to be as one of the world's top three mobile network infrastructure vendors serving more than 90 of the world's 100 largest tele-operators.

Case S's research interest in DD-SCALE project is the development of RDI efficiency analytics. So far the company is using a key performance indicator (KPI) approaches in evaluation of its RDI efficiency and the more conventional financial reporting, too. Case $\mathrm{S}$ has not only offshored activities but is also onshoring a $\mathrm{n}$ umber of IT development resources from local service companies.

However, the monitoring of less visible factors, which are more intellectual in nature, escapes beyond the current system efficacy. In addition to that, the multitude of the complexities outside the company's borders in S's ecosystem imply factors influencing on company performance but are not currently considered in the S's performance analytics. The more far-reaching vision of the results of the DD-SCALE project is improving the decision making methodology of the distribution management of new 
sites globally. The current methodology would benefit from the findings in improving the software design work performance metrics.

\subsection{Minicase 3: Common Innovation System Boost - Case A PLC}

The third organisation, Case A, is a part of a global leading company in power and automation technologies with high market positions in selected main business areas. A Group has more than 150000 employees in about 100 countries with 29 BEUR in revenues on Y2012. A Group is organized in five global divisions. The participating partner, case $\mathrm{A}$, is the Collaborative Production Management software business (CPM).

The main interest of CPM unit in the DD-SCALE project is the overall effectiveness of A's innovation system for CPM software business that needs to be improved to facilitate further business growth of the global business in high growth markets. This means in particular accelerating the idea-to-market deployment speed in the end-to-end process from innovation idea to its actual deployment in the marketplace. The overall innovation system covers multiple A business units addressing the various industrial markets and the common software platform technology development unit at the corporate level, which is fulfilling the common technology needs of all the target markets. The distributed organization and global nature of business make this challenge particularly interesting.

\subsection{Minicase 4: Organisational Development in a Multisite Environment - Case N}

The fourth and last company, Case $\mathrm{N}$, is 25 years old company, specialized in the B2B software business providing solutions for ship design and operations The company has approximately 175 employees and offices and/or representatives in 8 countries such as Japan, Korea, China, Singapore, India and Romania. More than 95 $\%$ of its 18 MEUR turnover comes from exports and their business operations are truly global. The company has grown steadily and is expanding both geographically and in sales development. The RDI resources are located in three countries: Finland, India and Romania. Since March 2014 case $\mathrm{N}$ is owned by a Japanese company and taken out of the stock exchange.

Starting point for the DD-SCALE project in the case $\mathrm{N}$ is linked to the continuous development of organization. Creation of the most efficient organizational forms demands enhanced fact-based metrics. Especially, a more accurate and reliable performance reporting of different RDI sites and teams is needed.

Compared to the other business functions, software development is more collaborative in nature. This is seen especially in commonly used modern process frameworks for software engineering. Currently the most favored way to organize the software development is based on agile methods such as SCRUM..

Therefore, the focus of $\mathrm{N}$ in the DD-SCALE project is centered on the research of the collaboration and performance of software engineering teams in the multisite ITorganization such as case $\mathrm{N}$. That means, for example, key performance indicators to 
monitor and determine the most efficient form of the organizations and distribution of work to maximize the overall performance of the company.

\section{Conclusive Remarks}

Our collaboration network of both research and educational institutes and global-scale software development organizations gives us an excellent viewpoint to both evaluate current situation and create new models and approaches for practice. Collaboration is ensured through active working with case companies and investigating on-going and background research. As it is noted by Prikladnicki and Audy [24] communications, methods, culture, and process details are just some of the facets of the unique characteristics of global software engineering environments. In the next ten years many of software development companies need to find their own competitive position in the evolving software markets, create a pattern of work practices capable for distribution of work, format new managerial practices for performance management in global value networks and promote innovations in open environments

Acknowledgments. The authors would like to express their gratitude to TEKES - the Finnish Funding Agency for Technology and Innovation and participating companies for commitment and start of the DD-SCALE research project and fostering collaboration in the ICT industry.

\section{References}

1. Ruohonen, M.: Nearshoring or Offshoring - Comparing ITO and BPO practices between India and Europe. In: Proceedings of the 6th CISTM Annual Conference on Information Science, Technology \& Management, New Delhi, India (2008)

2. Ruohonen, M.: Offshoring from Brazil or India - A European View. In: Proceedings of the 7th CISTM Annual Conference on Information Science, Technology \& Management, Gurgaon, India (2009)

3. Adelakun, O., Ruohonen, M.: Demystification of Latin Americas Offshore Outsourcing Destination. In: Proceedings of the 8th CISTM Annual Conference on Information Science, Technology \& Management, Tampere, Finland (2010)

4. Lacity, M.C., Willcocks, L.: Global information technology outsourcing: In search of business advantage. John Wiley \& Sons (2001)

5. Lacity, M., Willcocks, L., Cullen, S.: Global IT Outsourcing: 21st Century Search For Business Advantage. John Wiley \& Sons (2008)

6. Saxena, K.B.C., Ruohonen, M., Bharadwaj, S.S.: Strategic Outsourcing of Engineering Processes Using Agile Methods. In: Proceedings of the 8th CISTM Annual Conference on Information Science, Technology \& Management, Tampere, Finland (2010)

7. Walsham, G., Robey, F., Sahay, S.: Foreword: Special issue on information systems in developing countries. MIS Quarterly 31(2), 317-326 (2007)

8. Oshri, I., Kotlarsky, J., Willcocks, L.: Managing Dispersed Expertise in IT Offshore Outsourcing: Lessons from Tata Consultancy Services. MIS Quarterly Executive 6(2), 5365 (2007) 
9. Gartner: IT Spending Forecast, Q4 2013 Update (2014), http://www.gartner. com/technology/research/it-spending-forecast/ (checked February 11, 2014)

10. The Hindu Business Line (2014), http://www.thehindubusinessline. com/industry-and-economy/info-tech/indian-it-exports-togrow-1214-in-fy14-nasscom/article4407167.ece (checked February 11, 2014)

11. Heeks, R.: India's Software Industry: State Policy, Liberalization and Industrial Development. Sage Publications (1996)

12. Reddy, A., Ryman, A.: Software development and delivery performance measurement and management: Optimizing business value in software. IBM (2009), https://jazz . net/library/article/432/ (checked February 11, 2014)

13. Hudson, V.F.: The human touch: Cohesive cross-cultural teams begin with savvy relationship management. Industrial Engineer. Institute of Industrial Engineers, Inc. (IIE) (2007), http://www.highbeam.com/doc/1G1-169311055.html (checked February 11, 2014)

14. Thomas, D.C., Inkson, K.C.: Cultural intelligence: People skills for global business. Berrett-Koehler Publishers, San Francisco (2004)

15. Hofstede, G.: Culture's consequences. Sage Publications (1980)

16. Hofstede, G.: Cultures and organizations: Software of the Mind. McGraw-Hill, London (1991)

17. Hofstede, G.: Culture's consequence: International differences in work related values. Revised edition. Sage Publications (2001)

18. Trompenaars, F., Hampden-Turner, C.: Riding the Waves of Culture: Understanding Cultural Diversity in Global Business. Irwin (1998)

19. House, R., Hanges, P., Javidan, M., Dorfman, P., Gupta, V.: Culture, leadership, and organizations: The GLOBE study of 62 societies. Sage Publications (2004)

20. Jacob, N.: Cross-cultural investigations: Emerging concepts. Journal of Organizational Change Management 18(5), 514-528 (2005)

21. Fontaine, R.: Cross-cultural management: Six perspectives. Cross Cultural Management: An International Journal 14(2), 125-135 (2007)

22. Hevner, A.R., March, S.T., Park, J., Ram, S.: Design science in information systems research. MIS Quarterly 28(1), 75-105 (2004)

23. Jones, C.: Software Engineering Best Practices: Lessons from Successful Projects in the Top Companies. McGraw-Hill (2010)

24. Prikladnicki, R., Audy, J.L.N.: Managing Global Software Engineering: A Comparative Analysis of Offshore Outsourcing and the Internal Offshoring of Software Development. Information Systems Management 29(3), 216-232 (2012),

doi:10.1080/10580530.2012.687313 